\title{
INSULINOMA: A MULTICENTER AND RETROSPECTIVE ANALYSIS OF Endocrine tumors THE SPANISH EXPERIENCE DURING THREE DECADES EP-1085
}

Pedro Iglesias ${ }^{1}$, Christian Lafuente ${ }^{1}$, María Ángeles Martín Almendra², Antonio López-Guzmán ${ }^{3}$, José Carlos Castro ${ }^{4} \&$ Juan José Díez ${ }^{1}$

${ }^{1}$ Neuroendocrinology and Endocrine Tumor Unit. Department of Endocrinology. Hospital Ramón y Cajal. Madrid. Spain. Departments of Endocrinology. ${ }^{2}$ Hospital Virgen de la Concha. Zamora. Spain.

${ }^{3}$ Hospital Nuestra Señora de Sonsoles. Ávila. Spain. ${ }^{4}$ Hospital General. Segovia. Spain

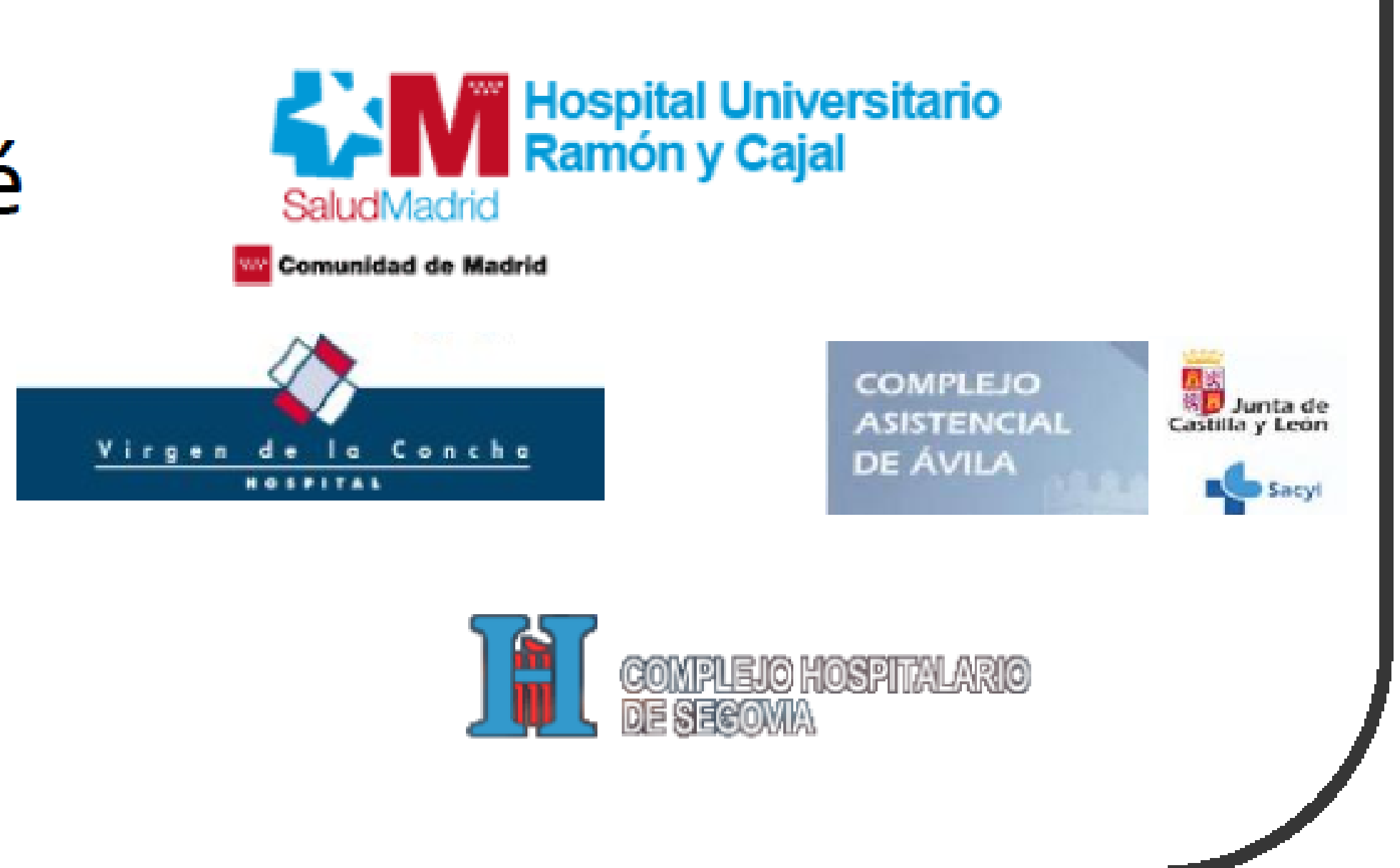

\section{INTRODUCTION}

Insulinoma (annual incidence, 4 cases per million inhabitants) is the most common functioning pancreatic neuroendocrine tumor. The series of insulinoma reported in Spain are scarce and have been usually performed in a small number of patients $(<10)$ from a single hospital.

\section{OBJECTIVE}

The aim of our study has been to retrospectively review a series of patients with insulinoma from our area studied and followed over the past 30 years.

\section{PATIENTS AND METHODS}

Retrospective study of all insulinomas diagnosed at the departments of Endocrinology in four Spanish hospitals: Ramón y Cajal (Madrid), Virgen de la Concha (Zamora), Nuestra Señora de Sonsoles (Avila) and Hospital General (Segovia).

Inclusion criteria were histological demonstration of tumor and/or the presence of biochemical and morphological criteria compatible with insulinoma. In each patient clinical, hormonal, diagnostic and therapeutic data were registered.

\section{RESULTS}

\section{Demographic data}

The distribution of patients according to study hospitals were: Hospital Ramón y Cajal, Madrid ( $\mathrm{n}=19,9$ of them belonging to the health area and 10 from other hospitals); Hospital Virgen de la Concha, Zamora $(n=5)$; hospital Nuestra Señora de Sonsoles, Avila $(n=3)$; and Hospital General Segovia ( $n=2)$. A positive correlation between the number of insulinomas diagnosed in each hospital and the number of inhabitants for the health area of each center was found (Figure 1).

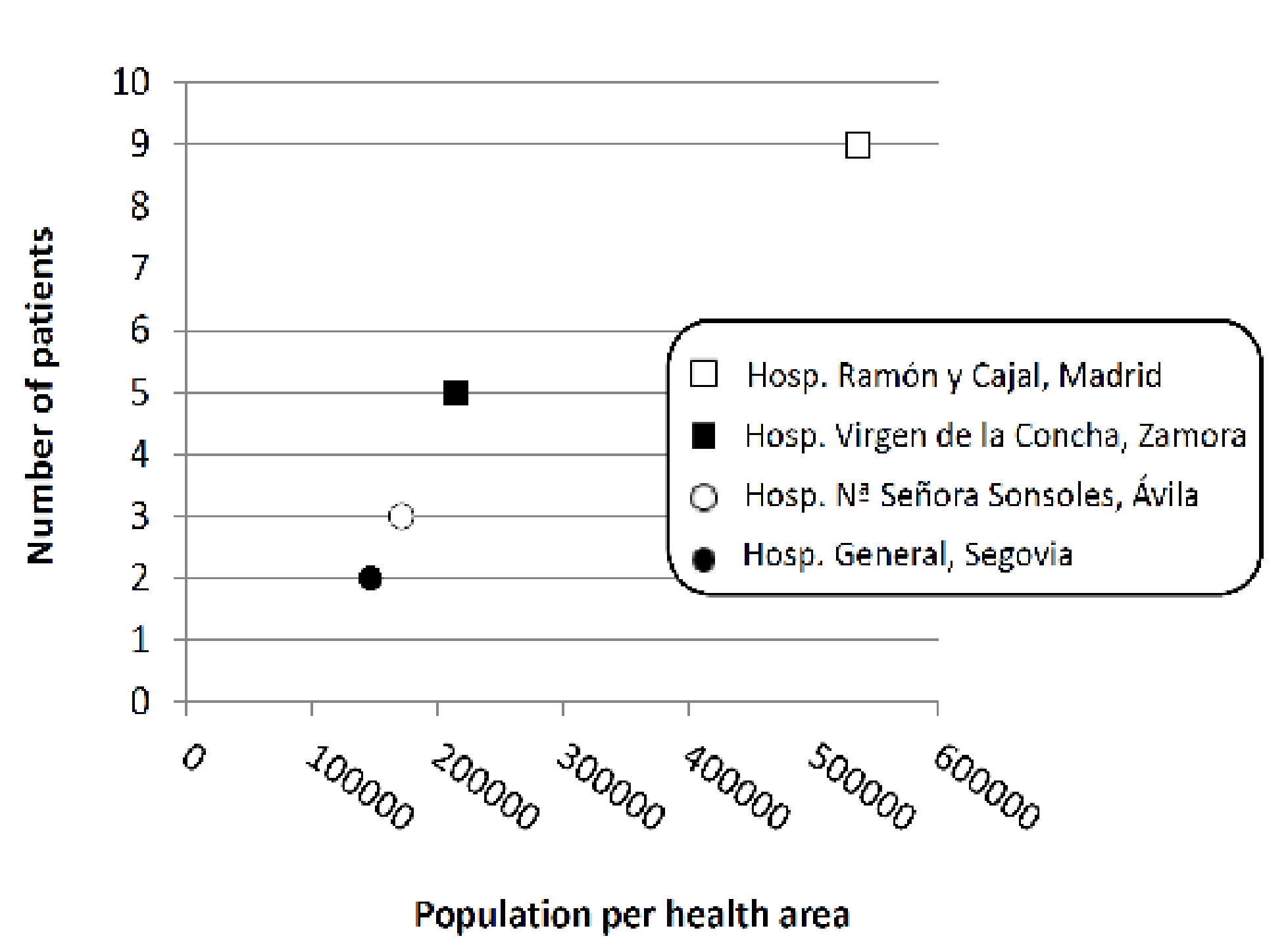

Figure 1. Correlation between number of cases of insulinoma diagnosed in the last 30 years and
population per hospital health area $(r=0,967 ; p=0,033)$.

\section{Clinical data}

Twenty nine patients [23 women (79.3\%) mean age $48.7 \pm 17.4$ years (range, 16-74) body mass index $28.5 \pm 5.6 \mathrm{~kg} / \mathrm{m} 2$ (range, 22.9 to 45.8)] were studied. Most of them $(41.4 \%)$ were diagnosed at $50-70$ years (Figure 2A).

The majority ( $n=18,62.1 \%)$ of patients showed fasting hypoglycemia, about a third (31\%) both fasting hypoglycemia and postprandial, and $6.9 \%$ only postprandial hypoglycemia (Figure 2B).

The tumor was sporadic in $26(89.7 \%)$ patients and in 3 (all women) associated to MEN 1. Three patients $(10.3 \%, 2$ women) had multiple insulinomas and 2 (6.9\%) patients ( 2 women of 48 and 65 respectively) had malignant insulinomas, both sporadic.

Table 1. Blood glucose, insulin and C-peptide at baseline at diagnosis, at the end of the prolonged fasting $(72 \mathrm{~h})$ test and in the latest clinical visit.

\begin{tabular}{|l|c|c|c|}
\cline { 2 - 4 } \multicolumn{1}{c|}{} & \multicolumn{1}{c|}{$\begin{array}{c}\text { Baseline at } \\
\text { diagnosis }\end{array}$} & $\begin{array}{c}\text { Fasting test } \\
(\mathbf{7 2} \mathbf{~})\end{array}$ & $\begin{array}{c}\text { Baseline at last } \\
\text { clinical visit }^{\mathbf{a}}\end{array}$ \\
\hline Glucose $(\mathrm{mg} / \mathrm{dl})$ & $64,1 \pm 22,3$ & $37,3 \pm 6,5^{* * *}$ & $102,8 \pm 26,0^{* * *}$ \\
\hline Insulin $(\mu \mathrm{U} / \mathrm{ml})$ & $24,4 \pm 24,5$ & $25 \pm 20,3$ & $10,2 \pm 15,3^{* *}$ \\
\hline C-peptide $(\mathrm{ng} / \mathrm{ml})$ & $3,17 \pm 1,86$ & $3,17 \pm 1,54$ & $1,74 \pm 1,30^{*}$ \\
\hline Nadir time $(\mathrm{h})$ & & $9,0 \pm 4,4$ & \\
\hline
\end{tabular}

${ }^{*} p<0,05 ; * * p<0,01 ; * * * p<0,001$ frente al valor basal al diagnóstico

Time to last clinical visit: median, 53 months; range 1-378.

Normal range: Glycemia 80-120 mg/dl; insulinemia $5-25 \mu \mathrm{U} / \mathrm{ml}$; and C-peptide 0,5 a $2,0 \mathrm{ng} / \mathrm{ml}$

Table 2. Data related to the tumor.

\begin{tabular}{|c|c|c|c|}
\hline & & Number & Percentage (\%) \\
\hline \multirow{4}{*}{ Localization } & Head & 11 & 37,9 \\
\hline & Body & 13 & 44,8 \\
\hline & Tale & 4 & 13,8 \\
\hline & Ectópic & 1 & 3,4 \\
\hline \multirow[t]{2}{*}{ Multifocality } & Single & 26 & 89,7 \\
\hline & Multiple & 3 & 10,3 \\
\hline \multirow{2}{*}{ Malignant } & No & 27 & 93,1 \\
\hline & Yes & 2 & 10,3 \\
\hline \multirow{3}{*}{ TNM staging } & IA & 23 & 88,5 \\
\hline & IB & 2 & 7,7 \\
\hline & IV & 1 & 3,8 \\
\hline \multirow{3}{*}{ Classification (OMS, 2010) } & G1 & 21 & 77,8 \\
\hline & G2 & 4 & 15,4 \\
\hline & G3 & 1 & 3,8 \\
\hline \multicolumn{2}{|l|}{ Size, mean \pm SD $(\mathrm{cm})$} & \multicolumn{2}{|c|}{$1,70 \pm 0,71$ (range, $1-4$ ) } \\
\hline
\end{tabular}

Table 3. Data related to therapeutic results and clinical outcome.

\begin{tabular}{|l|c|c|}
\cline { 2 - 3 } \multicolumn{1}{c|}{} & Number & Percentage (\%) \\
\hline Surgical intervention & 27 & 93,1 \\
\hline Curative surgery & 24 & 88,9 \\
\hline Reintervención & 3 & 11,1 \\
\hline Liver transplantation & 1 & 3,5 \\
\hline Tumor-related mortality & 1 & 3,5 \\
\hline Time of follow-up, mean \pm SD (months) & $76,7 \pm 86,2$ (range, $1-378$ ) \\
\hline
\end{tabular}

Therapy

Most patients ( $n=27,93.1 \%$ ) underwent surgery (median time from diagnosis to surgery, 4 months, interquartile range $2-7$ months). Data related to the tumor and therapeutic results are shown in tables 2 and 3.
Blood glucose, insulin and C-peptide are in Table 1. Glucagon test for glucose (Figure 3).

ocalizing study located the insulinoma in all patients except one $(n=28,96.5 \%)$ with (71.4\%; sensitivity $95.4 \%$ ). The rest was discovered by endoscopic ultrasonography $(n=3)$, MRI $(n=1)$, 68Ga-DOTA-exendin-4 , intraarterial injection of ultrasonography $(n=1)$. The diagnostic sensitivity for echo-endoscopy, abdominal ultrasonography and intraoperative MRI in study was $85 \%, 75 \%$ and $40 \%$, respectively.

\section{Hormonal and localizing study}

Age at diagnosis (vears)

Type of hypoglycen
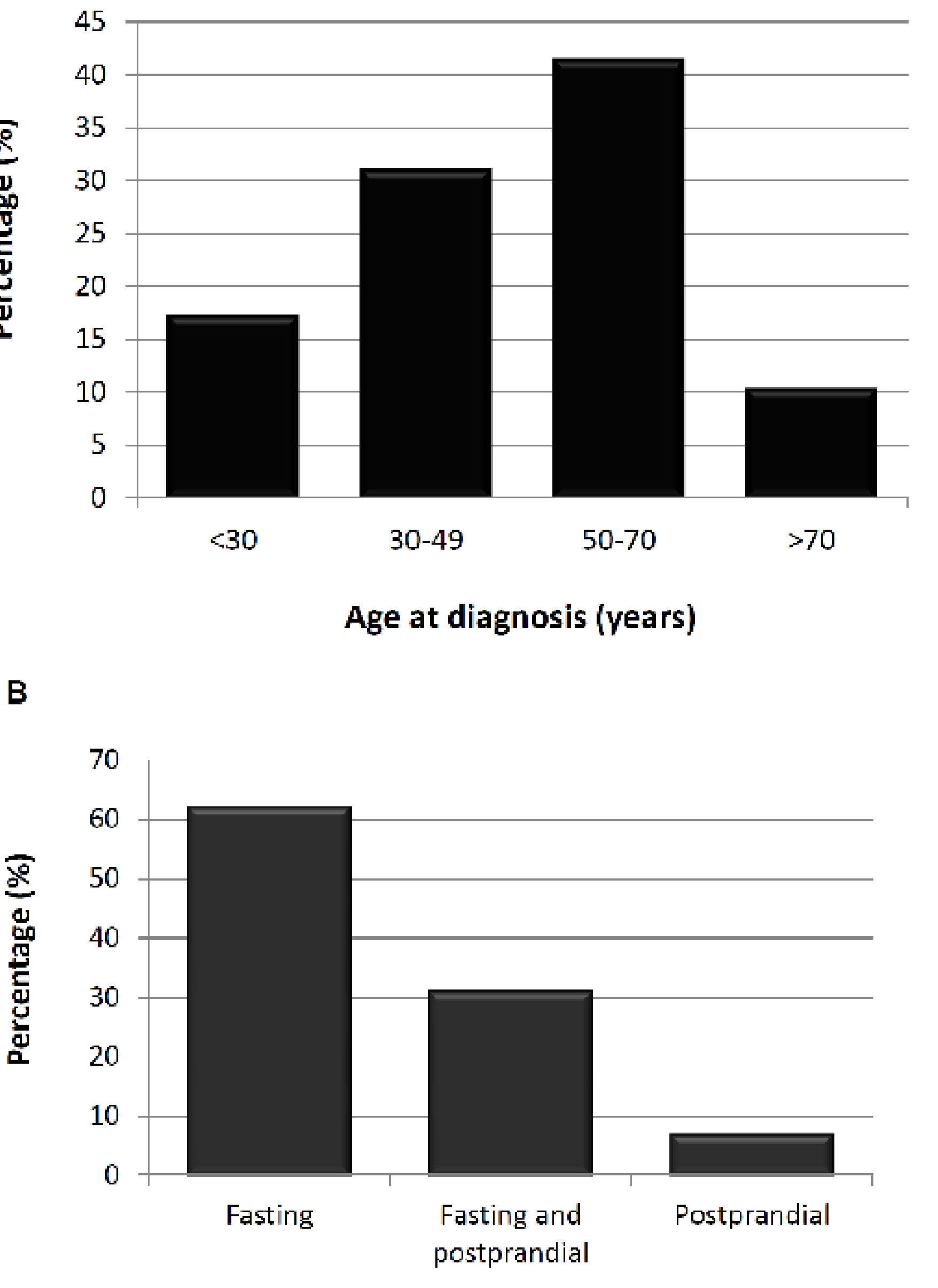

Figure 2. Percentage distribution of 29 patients with insulinoma according to age at diagnosis (A) and type of hypoglycemia (B)

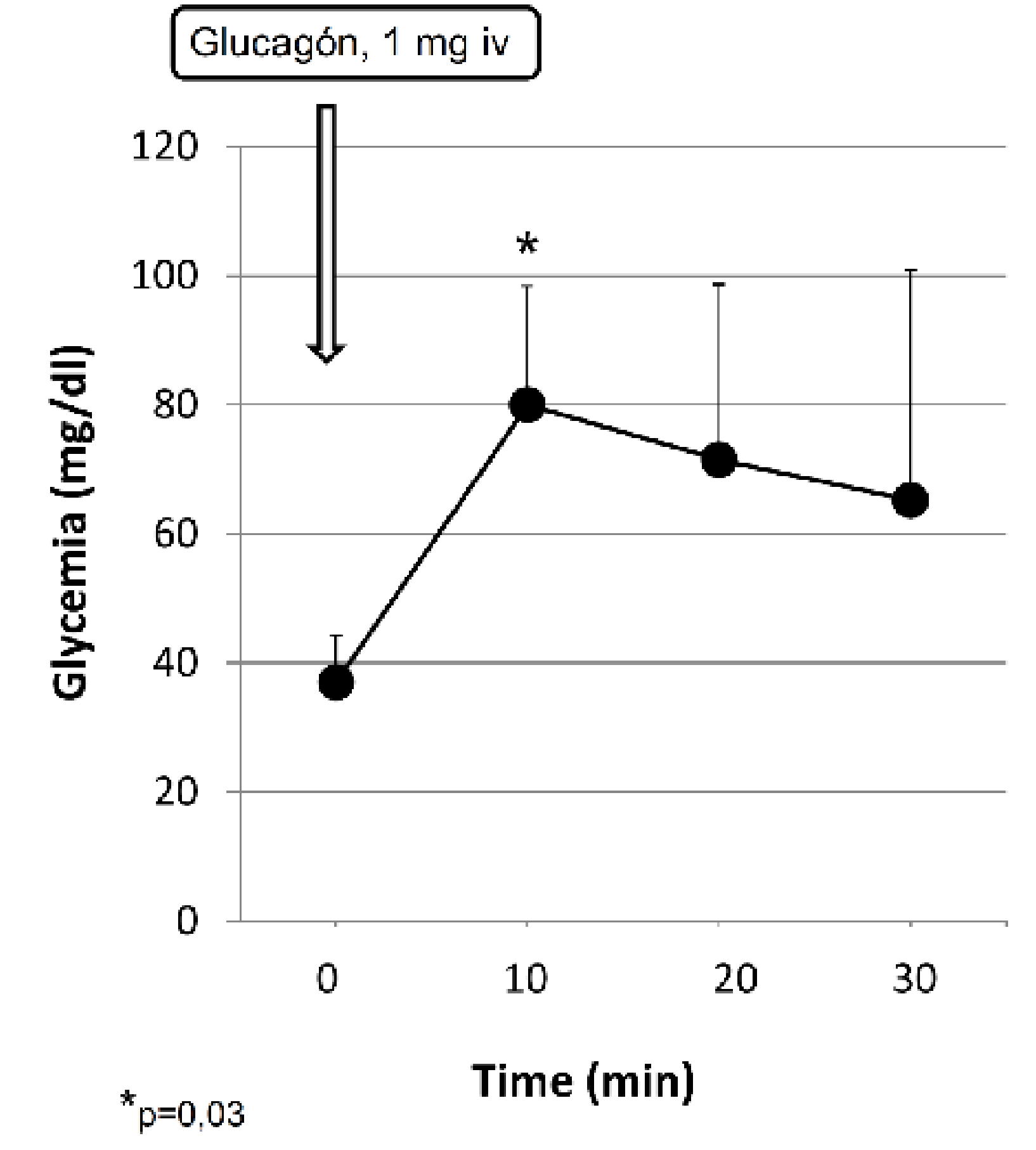

Figure 3. Serum glucose response to glucagon $(1 \mathrm{mg}$ iv) after fasting in 4 patients with insulinoma.

\section{Clinical follow-up}

Clinical follow-up was performed in 25 patients $(86.2 \%)$ for $76.7 \pm 86.2$ months (median, 53 months; range, 1-378). Data related to the clinical outcome are shown in table 3 . 